\title{
A new partial skeleton of Alligatorellus (Crocodyliformes) associated with echinoids from the Late Jurassic (Tithonian) lithographic limestone of Kelheim, S-Germany
}

\author{
Daniela Schwarz-Wings*, ${ }^{*}$, Nicole Klein ${ }^{2}$, Christian Neumann ${ }^{1}$ and Udo Resch ${ }^{3}$ \\ ${ }^{1}$ Museum für Naturkunde, Leibniz-Institut für Evolutions- und Biodiversitätsforschung an der Humboldt-Universität zu Berlin, 10115 Berlin, \\ Germany, e-mail: d.schwarz-wings@mfn-berlin.de \\ 2 Steinmann-Institut für Geologie, Mineralogie und Paläontologie, Universität Bonn, Nußallee 8, 53115 Bonn, Germany \\ ${ }^{3}$ Dietrichweg 12, 07749 Jena, Germany
}

Received 7 December 2010

Accepted 22 February 2011

Published 3 August 2011

\begin{abstract}
A slab from the Late Jurassic (Early Tithonian) lithographic limestone exhibiting skeletal material of an atoposaurid crocodyliform associated with four echinoids from the vicinity of Kelheim (S-Germany) is described. The atoposaurid is represented by a row of dorsal paravertebral osteoderms, caudal osteoderms, a caudal vertebra and haemapophyses, dorsal ribs, and parts of the right fore- and hindlimb. Some of the bones have been prepared out of the slab and most of them are preserved three-dimensionally, which is in contrast to the general much flattened preservation of atoposaurid skeletons. This well preserved specimen allows one of the most detailed descriptions of an atoposaurid limb skeleton so far, yielding in particular well preserved manual elements. By comparison with all other known atoposaurid taxa, the specimen can be determined to belong to the genus Alligatorellus based on an identical morphology of osteoderms. In contrast, a high ontogenetic variety and missing data make comparisons of limb ratios in different atoposaurids virtually useless for taxonomy. Femoral and tibial lengths suggest that this specimen is the largest atoposaurid known from the Solnhofen-Eichstätt region. It is suggested that the crocodyliform carcass has been washed into the lagoon and was subsequently embedded together with the tests of four holectypoid echinoids, which probably populated the lagoon.
\end{abstract}

\section{Introduction}

The Konservat-Lagerstätte of the Late Jurassic lithographic limestone of Bavaria (S-Germany) is famous for the outstanding preservation of invertebrate and vertebrate fossils. A recent collection survey carried out at the Museum für Naturkunde (Berlin) resulted in the recognition of a slab of lithographic limestone (MB.R.3632) from Kelheim (Franconian Alb, S-Germany) containing a partly associated skeleton of a small-sized crocodyliform, which is associated with four holectypoid echinoids, demonstrating a peculiar taphocenosis.

The small-sized crocodyliform can be determined to belong to Atoposauridae, a family of metasuchian crocodyliforms of generally small body size (not more than one meter in total length) and probably a partially terrestrial life style. Five genera (Alligatorium, Alligatorellus, Atoposaurus, Montsecosuchus, Theriosuchus) have been erected for Atoposauridae, which are partly monospecific and contain generally only few known fossil specimens. The fossil record of atoposaurids ranges from the Late Jurassic to the Late Cretaceous sediments of the Northern Hemisphere (Wellnhofer 1971; Buscalioni \& Sanz 1988; Wu et al. 1996; Schwarz \& Salisbury 2005; Martin et al. 2010; Lauprasert et al. 2011), however, the majority of localities concentrate in Europe. Fossils of Theriosuchus were found mainly in near-coastal environments with occasional salt water influx and, due to the characteristic teeth of the taxon, were recognized from a variety of localities throughout Europe. In contrast, skeletal remains of Alligatorium, Alligator-

* Corresponding author 
ellus, Atoposaurus, and Montsecosuchus are much rarer and occur exclusively in lithographic limestones ("Plattenkalke"), such as the Solnhofen limestones in southwestern Germany, Cerin in France, and Sierra de Montsec in Spain. These genera are considered a typical element in Jurassic-Cretaceous lagoonal environments. From the Late Jurassic lithographic limestones of Solnhofen-Eichstätt region, three genera (Atoposaurus, Alligatorellus, and Alligatorium) are known (Wellnhofer 1971), which comprise the species Atoposaurus oberndorferi Meyer, 1850, Alligatorium franconicum Ammon, 1905, Alligatorium paintenense Kuhn, 1961, and Alligatorellus beaumonti bavaricus Wellnhofer, 1971. Although atoposaurids are a constant faunal element in those lithographic limestones they remain relatively rare and their preservation between slabs of limestone produced an extreme flattening of the bones and allows examination only from one body side. Additionally, some of the specimens have been lost or destroyed during the Second World War. Consequently, these Late Jurassic atoposaurids of Bavaria/Germany remain rare and are only insufficiently known. In this respect, the new specimen from Kelheim is important, as it possesses some three-dimensionally preserved bones, and allows a better characterization particularly of atoposaurid forelimbs. In this paper, we give a detailed morphological description of the newly discovered specimen and discuss the reptile-echinoid assemblage and its implications for taphonomy and habitat reconstruction.

\section{Locality, stratigraphy, and associated echinoids}

As indicated on the label accompanying the crocodyliform-bearing limestone slab, the specimen was collected at Kelheim (Franconian Alb, S-Germany) and acquired by the Museum für Naturkunde from Krantz for a sum of 20 German Mark. Unfortunately, the label lacks both the date of acquisition and further locality information. Tithonian lithographic limestone is exposed in the vicinity of Kelheim (Goldberg) and can be referred to the Early Tithonian, Hybonotom-Zone, Rueppelianus Subzone (riedlingensis-Horizont) as indicated by the occurrence of the ammonite Gravesia gigas (G. Schweigert, personal communication 2007).

Four holectypoid echinoids belonging to the species Holectypus corallinus D'Orbigny, 1850 are exposed on the limestone bedding surface together with the crocodyliform bones. H. corallinus is a small-sized echinoid with a circular to subpentagonal outline and a plane oral surface. In profile, the test is hemispherical to subconical. H. corallinus is a common and widespread echinoid in the Late Jurassic, hitherto known from the Kimmeridgian across most parts of Europe. Species of the genus Holectypus were soft-bottom deposit-feeders which lived epifaunally or burrowed slightly below the sediment surface (Smith 1955).
The occurrence of Holectypus corallinus indicates occasional fully-marine conditions in the Kelheim lithographic limestone basin. Bantz (1969), Frickinger (1994, 1999), and Grawe-Baumeister et al. (2000) provided reviews of the echinoid faunas of the Late Jurassic lithographic limestone facies of southern Germany but did not mention Holectypus corallinus. Therefore, the occurrence of the four specimens associated with the atoposaurid crocodyliform represents the first record of this species from the lithographic limestone facies so far. Moreover, the stratigraphic range of this species is herewith extended towards the Tithonian. However, information about Tithonian echinoid faunas is generally scarce.

\section{Systematic Paleontology}

Superorder Crocodylomorpha Walker, 1970

Grandorder Crocodyliformes Hay, 1930

Order Metasuchia Sereno, Larsson, Sidor \& Gado, 2001

Family Atoposauridae Gervais, 1871

Genus Alligatorellus Gervais, 1871

\section{Alligatorellus sp. \\ Type species. Alligatorellus beaumonti Gervais, 1871 \\ Type locality and horizon. Cerin, France; Upper Kimmeridgian.}

Referred specimen. The rectangular limestone slab yielding the crocodyliform and the echinoids (measurements: $2800 \times 1700 \mathrm{~mm}$ ) is housed in the vertebrate palaeozoology collection of the Museum für Naturkunde (MB.R.3632, Fig. 1).

Diagnosis. According to Wellnhofer (1971, p. 144) large-sized atoposaurids (420 to $550 \mathrm{~mm}$ ) with acute-triangular skull and large orbit, supratemporal fossae not internally opened (fenestrated) and connected to the orbit by a superficial furrow, nasal aperture divided, tail longer than half of the precaudal body length, biserial osteodermal shield from nuchal to caudal region, single osteoderms sculpted, lateral keel on nuchal and dorsal osteoderms, whereas caudal osteoderms bear a more medial keel, ventral armour with two rows of scutes in the tail region, ventral scutes oval and medially keeled.

Remark. Wellnhofer (1971) divides the species Alligatorellus beaumonti into the two subspecies Alligatorellus beaumonti beaumonti and Alligatorellus beaumonti bavaricus basing on their different sizes and localities.

\section{Description}

Preserved elements and their orientation on slab. The bones are very well preserved, mostly undistorted and only slightly compressed. The right femur and metatarsal I are preserved only by impressions on the slab. Recently, the tibia, metatarsal II to IV, calcaneus, three pedal phalanges and a pedal ungual phalanx were taken out and fully prepared. With the exception of calcaneus and pedal phalanges, the original positions of the bones are visible as impressions on the slab (Fig. 1). 


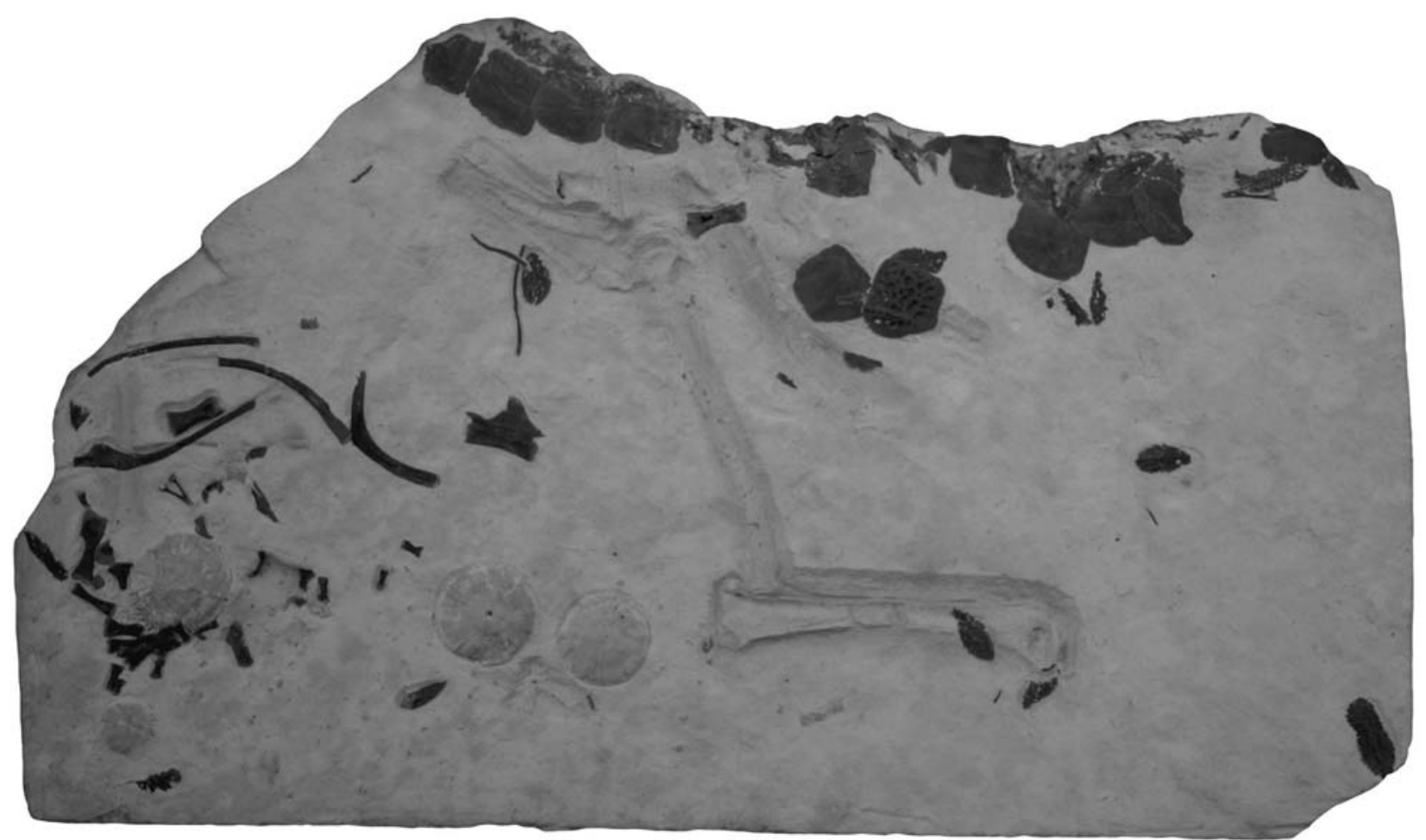

A

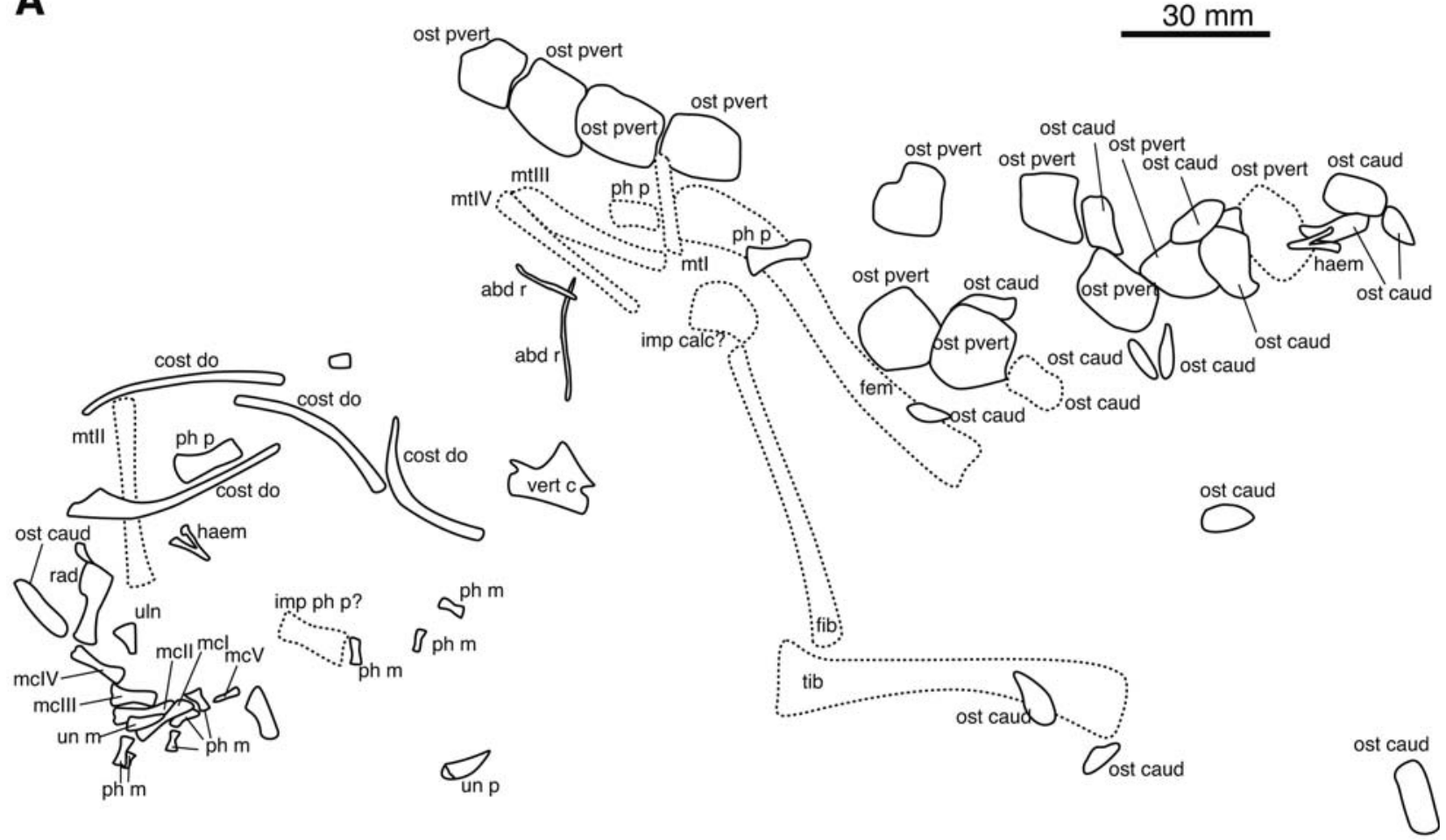

B

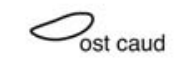

Figure 1. MB.R.3632, slab containing the skeleton of the atoposaurid Alligatorellus sp. and four holectypoid echinoids belonging to the species Holectypus corallinus D'Orbigny, 1850. A. Photograph of the whole slab; B. Outline drawing of skeletal structures that can be identified as belonging to the crocodyliform; solid lines represent bones attached to the slab, hatched lines refer to bone impressions on the slab. Abbreviations: cost do - dorsal rib; abd r - abdominal rib; fem - femur; fib - fibula; haem haemapophysis; imp calc - impression possibly of calcaneus; imp ph p - impression possibly of pedal phalanx; $\mathbf{m c I}-\mathbf{V}$ - first to fifth metacarpal; mtI-IV - first to fourth metatarsal; ost caud - caudal osteoderm; ost pvert - paravertebral osteoderm; ph m manual phalanx; ph p - pedal phalanx; rad - radiale; tib - tibia; uln - ulnare; un p - ungual phalanx; vert c - caudal vertebra. 
The crocodyliform bones on the slab seem to correspond to their anatomical position with some drift having taken place. An incomplete row of dorsal paravertebral osteoderms preserved partly in articulation and exposed from internally is preserved along one of the longer margins of the slab. Laterally and caudally adjacent to them lie two additional dorsal osteoderms and some more rounded caudal osteoderms. At the broken edge of the slab and below the osteodermal row, scanty fragments of dorsal vertebrae are exposed. A single well preserved medial caudal vertebra is deposited nearly at the centre of the slab and exposed from laterally. A complete haemapophysis is pressed onto one of the more distal caudal osteoderms and visible from cranially or caudally. Seven small osteoderms from the dorsal or ventral side of the tail have been deposited on different areas of the slab, partly exposed from externally and from internally.

Laterally to the osteodermal row lie remnants of the right hindlimb in the centre of the slab. Within the impression of the right femur, a pedal phalanx is exposed from the ventral side. Right astragalus and fibula are deposited in an angle of ca. $45^{\circ}$ from the femur impression, whereas the right tibia lies distally adjacent to the fibula and with an angle of $100^{\circ}$ to the latter. Cranially adjacent to femur, fibula and astragalus, impressions of Mt I, III and IV are visible, but only Mt III and IV are preserved as body fossils. Two abdominal ribs lie laterally to the metatarsals. A pedal ungual phalanx is visible far from the preserved hindlimb elements and close to one of the echinoids (Fig. 1).

Parts of the right manus, four dorsal ribs, a pedal phalanx, and an echinoid are clustered together in a position on the short side of the slab. The dorsal ribs lie close to each other and are partly overlain by metatarsal II. Between the ribs lies another proximal pedal phalanx, and distally to it a small, isolated haemapophysis. Distally to Mt II lies a radiale and ulnare, and distally to the latter, the metacarpus is spread out around one of the echinoids. The metacarpals I to III are still partly associated, whereas metacarpal IV and $\mathrm{V}$ are slightly displaced. The number of manual phalanges is incomplete and the phalanges are deposited around the metacarpal bones.

Dorsal and abdominal ribs. The four dorsal ribs preserved on the slab are from the caudal part of the trunk and slightly differ in length and robustness from each other (Fig. 1). Whereas the rib's bone is incompletely preserved, their original length can be determined from their impressions on the slab. The most cranial of the four dorsal ribs is also the longest preserved rib (Table 1). The rib head is slightly bent away from the rib shaft and divided into a capitular and tubercular articular surface separated from each other by a weak indentation. The rod-like rib shaft tapers from proximally to distally.

Two other dorsal ribs (Table 1) had a position in the trunk caudally to the largest preserved dorsal rib. The rib heads form a simple, cup-shaped tubercular articular surface that is only slightly broadened and slightly bent away from the rib shaft. The distal end of this rib is very weakly expanded and rugose, indicating articulation with the cartilaginous rib elements. The smallest preserved dorsal rib (Table 1) is more robust than the other dorsal ribs. The rib shaft has a distinct boomerang-shaped curvature. Its preserved distal end is thickened and rugose, and it is likely that this rib represents one of the caudalmost dorsal ribs in the trunk of the specimen.

Additionally, two abdominal ribs are preserved on the slab (Fig. 1). These abdominal ribs are very delicate and irregularly twisted along their longitudinal axis.

Table 1. Measurements of length of bones of MB.R.3632.

\begin{tabular}{|c|c|}
\hline Element & length in $\mathrm{mm}$ \\
\hline Dorsal rib & 46.1 \\
\hline Dorsal rib & 44.7 \\
\hline Dorsal rib & 42.1 \\
\hline Dorsal rib & 27.1 \\
\hline Abdominal ribs & 23.4 \\
\hline Abdominal ribs & 13.7 \\
\hline Phalanx of manus & 5.2 \\
\hline Phalanx of manus & 3.2 \\
\hline Phalanx of manus & 5.7 \\
\hline Phalanx of manus & 5.2 \\
\hline Phalanx of manus & 4.0 \\
\hline Phalanx of manus & 4.8 \\
\hline Phalanx of manus & 4.5 \\
\hline Phalanx of manus & 4.7 \\
\hline Ungual phalanx of manus & 6.1 \\
\hline Ungual phalanx of manus & 4.3 \\
\hline Phalanx of pes & 12.7 \\
\hline Phalanx of pes & 10.4 \\
\hline Phalanx of pes & 8.5 \\
\hline Phalanx of pes & 8.1 \\
\hline Phalanx of pes & 11.6 \\
\hline Ungual phalanx of pes & 8.3 \\
\hline Ungual phalanx of pes & 10.2 \\
\hline Right radiale & 15.1 \\
\hline Right ulnare & $>5.7$ \\
\hline Metacarpal I & 11.1 \\
\hline Metacarpal II & 11.2 \\
\hline Metacarpal III & 8.6 \\
\hline Metacarpal IV & 10.7 \\
\hline Metacarpal V & 5.5 \\
\hline Right femur imprint & 74.7 \\
\hline Right tibia & 68.3 \\
\hline Right fibula & 61.9 \\
\hline Metatarsal II & 37.9 \\
\hline Metatarsal III & 32.6 \\
\hline Metatarsal IV & 33.8 \\
\hline
\end{tabular}


Caudal vertebra and haemapophyses. An isolated middle caudal vertebra is exposed from its left lateral side and is $11.5 \mathrm{~mm}$ high (Fig. 1). In lateral aspect, the vertebra has a very elongated vertebral centrum that is $15.5 \mathrm{~mm}$ long and $4.3 \mathrm{~mm}$ high. The vertebra is platycoelous. The vertebral centrum is completely fused to the neural arch and no trace of a neurocentral suture is visible. The lateral face of the vertebral centrum bears a long oval cranial fossa and a small caudal fossa, which are bounded against the neural arch with a very faint, rounded crest. With $13.7 \mathrm{~mm}$, the neural arch is nearly as long as the vertebral centrum. The pre- and the postzygapophyses represent simple and small rods that overhang the vertebral centrum. In lateral aspect, the neural spine is rounded triangular, being basally very long and tapering strongly towards its apex. The apex of the neural spine is position at mid-length of the vertebra and slightly cranially bent. The lateral surface of the neural spine is smooth.

Two isolated haemapophyses on the slab are preserved with their cranial or caudal side. They have both the typical chevron shape forming a base of one third the length of the whole haemapophysis, from which a left and a right branch diverge. Each branch bears dorsally a rounded square articular surface for the caudal vertebrae. The size of both haemapophyses indicates that they most probably come from the medial tail region.

Carpals and manus. The right radiale is comparatively larger in size and one third longer than the first metacarpal (Fig. 1, Table 1). The radiale has a characteristic, hatchet-shaped morphology with a squarish proximal end, a long and slightly constricted shaft and a distal expansion. The proximal articular surface is separated into a proximally directed radial articular surface and a laterally directed articular surface for the ulnare. The broad cranial face of the proximal articular surface is medially depressed. The distal articular surface forms a transversely oval articular surface for the distal carpals. The radial face is slightly rugose. One nearly circular distal carpal, probably the pisiforme, is preserved directly adjacent to the distal articular suface of the radiale.

The right ulnare is only preserved with its proximal half. It is distinctly smaller than the radiale (Fig. 1, Table 1). The proximal end is spatulate and expanded, whereas the shaft is very slender with a circular crosssection.

The five metacarpals (Mc I-V) of the right manus are slightly disarticulated and exposed from their ventral side within the slab (Fig. 1). Mc I is the longest and most slender of the metacarpals (Table 1). Mc I has an expanded, spatulate proximal articular surface that is depressed at its medial face. The shaft is slightly constricted and the distal articular surface slightly expanded. The distal articular surface possesses two small hemicondyles that are expanding onto the rugose ventral face of Mc I. Mc II has a proximal articular surface which is partly obscured by Mc I. Morphologically, it is very similar to Mc I, but possesses a distal articular surface in which the hemicondyles are only indistinctly separated from each other. Mc III is considerably shorter and stouter than Mc I and II (Table 1). Its proximal articular surface is strongly expanded, spatulate and forms a medial projection. Its distal articular surface is developed into a distinct spool-shape. Morphologically, Mc IV does not deviate strongly from Mc I and II, except that it has a rather simple distal articular surface that forms only a single condyle. $\mathrm{Mc} \mathrm{V}$ is rod-like and the smallest of the metacarpals (Table 1). Mc V expands only weakly proximally and has a simple distal articular surface.

Eight proximal manual phalanges are present at the slab (Fig. 1). Additionally, two manual ungual phalanges are preserved. The phalanges vary slightly in size and width, but are rather similar in morphology to the pedal phalanges, possessing generally a slightly spatulate proximal articular surface, a weakly constricted shaft and a distal articular surface with two weakly divided hemicondyles. The manual ungual phalanges are proximally high and taper distal to a tip, being slightly curved in the middle. A weak furrow marks the lateral surface of the manual phalanges.

Femur. The preserved femoral impression on the slab gives an idea about its length, curvature and proportions (Fig. 1, Table 1). The shaft is sigmoidally curved. The proximal margin is weakly convex and not expanded in relation to the rest of the proximal extremity. The distal extremity is rounded, forming the impression of the distal femoral condyle. The femur is $1 / 10$ longer than the tibia.

Tibia and fibula. The right tibia is three-dimensionally preserved. The bone is proximally and distally strongly craniocaudally compressed, whereas the shaft seems to have retained its original oval cross-section (Figs 2AB). The tibia is slender in proportions (Table 1) and is mostly straight, only the proximal third curves slightly caudally from the shaft. The tibial head is expanded, but due to the compression the proximal articular surface does not show the typical triradial structure of a crocodyliform tibia, but forms an oval surface. In cranial aspect, the proximal extremity is divided by a medial ridge into a small, bevelled lateral area that forms the articular surface for the fibula, and a large medial area that is slightly depressed. Both areas are covered by strong, vertical striae. At the transition to the tibial shaft, there is another, proximodistally elongated depression with delicate striae. In caudal aspect, the proximal end is depressed and bears medially a deep central pit, presumably produced by diagenetic calcite growth (Fig. 2A). The cnemial crest is a small but distinct ridge that extends centrally from the upper midshaft area into the cranial proximal depression. The distal extremity is expanded from the tibial shaft and forms a weak medial process. On the flattened cranial side, a lateral vertical ridge bounds a small and bevelled lat- 


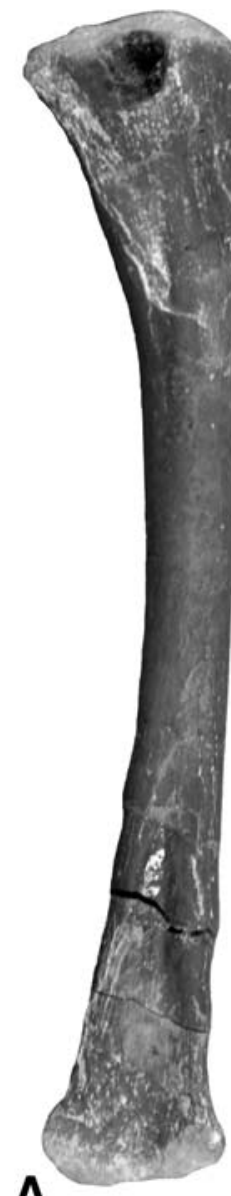

A

B

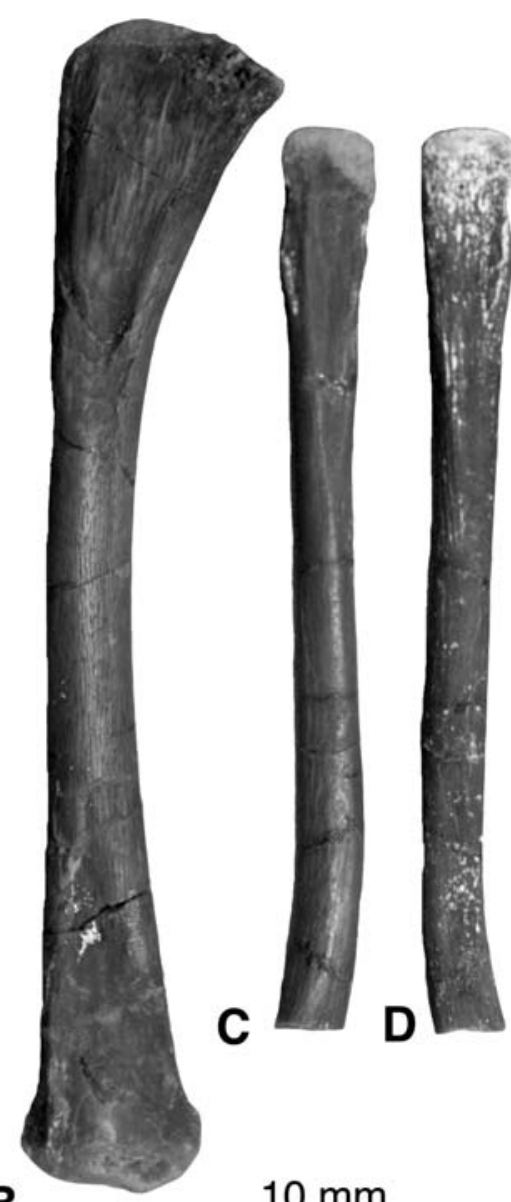

$10 \mathrm{~mm}$

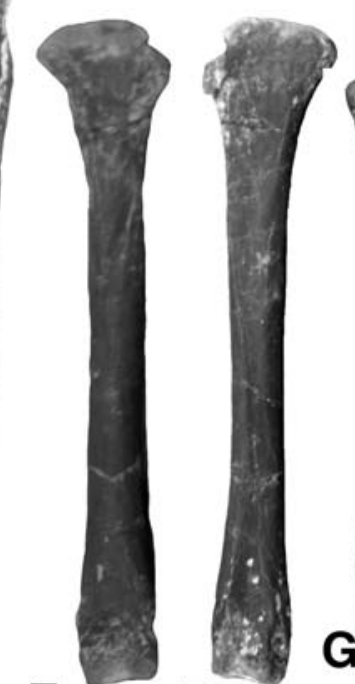

E

$\mathbf{F}$
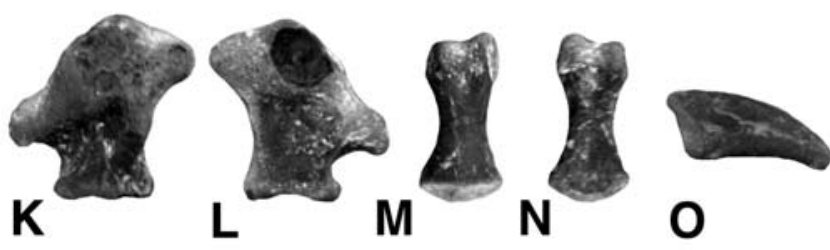

0

Figure 2. MB.R.3632, bones prepared from matrix and belonging to atoposaurid Alligatorellus sp. A-B. Right tibia, (A) in caudal, (B) in cranial aspect; C-D. Incomplete right fibula, (C) in lateral, (D) in medial aspect; E-F. Metatarsal II, (E) in dorsal, (F) in ventral aspect; G-H. Metatarsal III, (G) in dorsal, (H) in ventral aspect; I-J. Metatarsal IV, (I) in dorsal, (J) in ventral aspect; KL. Right calcaneus, $(\mathrm{K})$ in cranial, $(\mathrm{L})$ in caudal aspect. M-N. Pedal phalanx, (M) in dorsal, (N) in ventral aspect; O. Ungual phalanx in lateral aspect.

eral area (Fig. 2B). The main cranial surface of the distal extremity is covered by striae. At the distal margin, a weak mound is visible medially. The caudal side of the distal extremity is deeply depressed, with the depression being widest at the distal tibial margin and tapering proximally, but reaching up to the distal fourth of the shaft length.

The right fibula is incomplete with the distal end missing (Figs 2C-D). The impression in the slab allows a restoration of its original length (Table 1). Thus, the fibula reaches $90 \%$ of the length of the tibia. The fibula possesses a slender shaft and a weakly expanded proximal end. The bone is weakly curved proximally and distally, forming a faint s-shape. The proximal end is strongly flattened, whereas the shaft has retained its oval cross-section. The proximal extremity exposes in lateral aspect the articular surface with the tibia, and is distally to that surface centrally depressed. The depression continues on the fibular shaft along its proximal third. A rounded caudal ridge is also visible on the lateral surface (Fig. 2C). The medial surface of the proximal extremity of the fibula is also weakly depressed and rugose.
Calcaneus and pes. The considerably compressed right calcaneus is $11.9 \mathrm{~mm}$ long and $10.5 \mathrm{~mm}$ high. In cranial aspect, the calcaneus possesses a squarish proximal body that is slightly constricted, a large calcaneal tuber that is distally and laterally positioned, and a medial articular surface for the astragalus that forms a small, acute process (Figs $2 \mathrm{~K}-\mathrm{L}$ ). The calcaneal tuber bears cranially a large and rounded triangular articular face for the astragalus. The medial articular surface overlapping the astragalus is saddle-shaped and flattened on the caudal side of the calcaneum. A large, circular deep excavation is visible distally on the cranial side and probably produced by calcitic growth.

The impression of $\mathrm{Mt} \mathrm{I}$ is incomplete and too weak to estimate the morphology and proportions of the bone. The completely preserved Mt II-IV are proximally flattened, whereas the distal extremity and the shaft have retained their original proportions. Mt II is a long, slender bone with an expanded proximal end, a straight shaft, and a very weakly expanded distal end (Figs 2E-F). The proximal extremity is spatulate and forms a slight medial projection. The dorsal and ventral faces are slightly rugose. The shaft of Mt II is transver- 
sely oval in cross-section, and has a smooth surface. The distal extremity forms a distinct distal articular surface with two hemicondyles connected medially and expanding slightly onto the ventral side of the distal extremity. The dorsal face of the distal extremity is very weakly depressed and rugose. In contrast, the ventral surface bears a central, circular and deep depression between the two hemicondyles. The broadened lateral and medial distal margins are rugose.

Mt III possesses a less expanded proximal extremity (Figs $2 \mathrm{G}-\mathrm{H}$ ) with a weak lateral projection. The shaft is straight in cross-section, oval in cross-section, and expands slightly in its proximal half until the proximal extremity. The proximal articular surface expands onto the dorsal face of the proximal extremity, where it forms a distinct central bulge. Around this bulge, the dorsal surface bears longitudinally directed striae. The ventral surface of the proximal extremity bears a deep proximodistally directed central depression. The distal extremity forms a typical spool-shape that is present also in the phalanges: Its distal articular surface is square and divided into two hemicondyles separated by a weak median sulcus, and the lateral and medial margins are distinctly broadened and bear a circular depression. Dorsal and ventral face of the distal extremity are centrally slightly depressed and rugose.

Mt IV is the most slender of all preserved metatarsals (Figs 2I-J). Its shaft is straight and oval in crosssection. Its proximal extremity is very weakly expanded, spatulate and forms a medial projection. The proximal extremity is dorsally and ventrally slightly rugose. The distal extremity shows a similar spool-shape as Mt III and its ventral and dorsal face are faintly depressed and slightly rugose.

Five proximal and two ungual pedal phalanges are preserved on the slab, one ungual and three pedal phalanges of them prepared. All pedal phalanges are short and stout (Figs $2 \mathrm{M}-\mathrm{N})$. The shaft is constricted, whereas the proximal end is strongly and the distal end slightly expanded. The proximal extremity is slightly irregular in its proportions, being laterally slightly higher than medially. The proximal articular surface is roughly transversely oval and bowl-like depressed. The distal extremity forms a spool-shape with lateral and medial depression on the margin and two little distal hemicondyles that expand onto the ventral surface. The dorsal and ventral face of the distal extremity are depressed and rugose with the impression being deeper on the dorsal face.

Two ungual phalanges are preserved (Fig. 2O). The fully prepared ungual phalanx is curved, its body is dorsally convex and ventrally concave. The ungual phalanx tapers from the base to its distal end and distally forms a blunt tip. The proximal articular surface is slightly oblique and oval in outline, being dorsally longer than ventrally and medially vaulted. The lateral and medial surfaces are slightly rugose and bear a very weak sulcus that parallels the dorsal margin in its curvature.
Osteoderms. All in all, ten dorsal paravertebral osteoderms and one additional impression of a paravertebral osteoderm are preserved on the slab (Fig. 1). With the exception of one, all are preserved from their internal side. Partially, these osteoderms are preserved with a slight overlap that reflects their natural imbricating position. The paravertebral osteoderms are all very similar in size, being ca. $16 \mathrm{~mm}$ long and $16.5 \mathrm{~mm}$ wide. Their outline is squarish with rounded edges, but the lateral margin is more convex, and the osteoderms are only very weakly internally arched. The cranial and caudal margins are smooth, whereas the medial and lateral margins are weakly serrated. The exposed external surface shows a shallow cranio-caudally oriented keel in the lateral third of the osteodermal surface that occupies three fourths of the length of the osteoderm. Most of the external surface is sculptured with regularly spaced deep circular pits of varying sizes, except a small bend parallel to the cranial margin of the osteoderm, which is smooth and unsculptured. The internal surface of the osteoderms bears a week median and craniocaudally directed keel that extends from the cranial osteodermal margin over two-thirds of the length of the osteoderm. The internal surface of the osteoderms bears a few circular nutricious foramina and in places a very delicate criss-crossing pattern of striae.

16 more incomplete caudal osteoderms are scattered across the slab, all preserved in external and internal aspect (Fig. 1). These osteoderms are of varying size ( $9 \mathrm{~mm}$ to $18 \mathrm{~mm}$ length) and take either the form of an elongated oval or that of a narrow oval. They were positioned most probably at the sides and ventral surface of the tail. The osteoderms are all regularly externally sculptured and bear a median, longitudinal keeled. The margin is serrated. The internal surface of these osteoderms bears some single striae and some nutrient foramina.

\section{Discussion}

\section{Taxonomic assignment of the crocodyliform remains}

MB.R.3632 is a slab that consists of the incomplete and disarticulated left half of an armoured small crocodyliform. The most conspicuous features are the large radiale of the manus, the hindlimb bones and their proportions, and the distinct sculptured and keeled osteoderms. Comparisons with other atoposaurids with a preserved radiale show an essentially similar morphology of the radiale as postulated by Buscalioni \& Sanz (1990). Because the neurocentral sutures of caudal vertebrae in crocodylians fuse already after hatchling (Brochu 1996), nothing can be said about the ontogenetic stage of the animal. However, the degree of ossification of the bones, mainly the metatarsals, suggests at least a subadult individual. On the basis of femoral length of extant alligators (Farlow et al. 2005) and measurements published in Wellnhofer (1971), the total body length of the spe- 
cimen can be estimated to be around $100 \mathrm{~cm}$. By its length of the femur and tibia, and the reconstructed total body length, MB.R.3632 is the largest atoposaurid skeleton known from the Solnhofen-Eichstätt region, but also in comparison to the other "classical" atoposaurid localities Cerin (France) and Montsec (Spain).

The Solnhofen-Eichstätt region has yielded two distinctly different groups of crocodyliforms so far. The first group comprises thalattosuchians, large marine crocodylians such as Steneosaurus, Geosaurus and Dakosaurus (Westphal 1965; Wellnhofer 1971; Andrade et al. 2010). The second group comprises atoposaurids, small-sized terrestrially to amphibious crocodyliforms of the genera Atoposaurus, Alligatorellus, and Alligatorium (e.g., Wellnhofer 1971). According to the preserved skeletal remains of MB.R.3632, thalattosuchians can be safely excluded as to their differences especially in osteoderm morphology and hindlimb bone proportions. Due to the relatively small size of the individual, osteological similarities with atoposaurids, and the stratigraphic position of the locality, a comparison with the atoposaurids Atoposaurus Meyer, 1850, Alligatorellus Gervais, 1871, and Alligatorium Jourdan, 1862 seems reasonable. All of these genera have been described with species from the Solnhofen-Eichstätt region, from the contemporary locality of Cerin in France, and one (Montsecosuchus ("Alligatorium") depereti, Buscalioni \& Sanz 1988) from the lower Barremian Montsec limestone quarry in Spain.

According to Buscalioni \& Sanz (1988) the status of the genus Atoposaurus is uncertain and the extremely small size of the specimens makes it possible that they are juveniles of other taxa. Two species, A.jourdani from Cerin, and $A$. oberdorfi with one specimen from Kelheim and one from Schernfeld were described (Wellnhofer 1971), but all are poorly preserved. All species of Atoposaurus are small $(<20.0 \mathrm{~cm})$ and no osteoderms have been found with the skeletons, which has been used as a diagnostic character (Wellnhofer 1971). Although the absence of osteoderms is difficult to take as a taxonomic value, as it might be taphonomic or ontogenetic (i.e., not ossified osteoderms, which would coincide with the extremely small size of the specimens), the presence of osteoderms in MB.R.3632 from the same locality Kelheim might indicate indeed the taxonomic value of this character. Interestingly, measurements of radiale and Mc I given by Wellnhofer (1971) for the two specimens of A. oberndorferi show a significant difference in their proportions: in the Kelheim specimen, the radiale is significantly shorter when compared to Mc I, whereas in the Schernfeld specimen and all other atoposaurids from the Solnhofen-Eichstätt region including MB.R.3632, the radiale is longer than the metacarpals (Table 2). As the Schernfeld specimen is smaller than that from Kelheim but shows a condition of the radiale similar to other atoposaurids from the Solnhofen-Eichstätt region, ontogenetic variation is unlikely, and a taphonomic condition causing the shorter radiale in the Kelheim specimen is more plausible.
The genus Alligatorium comprises specimens with a known body length of $42.0 \mathrm{~cm}$ to $55.0 \mathrm{~cm}$. The first described species $A$. meyeri Gervais, 1871 is from Cerin in France. Later, two other species, A. franconicum Ammon, 1905 and A.paintenense Kuhn, 1961, were described from Painten. Unfortunately, the type specimen of Alligatorium franconicum appears to have been lost, whereas the type specimen of Alligatorium paintenense was destroyed in 1944 in the course of the Second World War. Wellnhofer (1971) discussed the uncertain status of Alligatorium franconicum Ammon, 1905, which consisted only of an isolated right pelvis and hindlimb without distinct skeletal features. Buscalioni \& Sanz (1988) consider $A$. franconicum as nomen dubium. Comparison between A. meyeri from Cerin (Wellnhofer 1971, fig. 11a) and the only existing cast of $A$.paintenense (PALMUC Nr. 1971 I 104) shows that both can be distinguished by their dorsal osteoderms which are scute-like and unkeeled in $A$. meyeri, and broader than long with two distinct osteodermal keels in A. paintenense. This difference would relate to significant differences in the systematic relationship between the two taxa and the biomechanics of the trunk (Salisbury \& Frey 2001; Salisbury et al. 2006), and makes a generic separation between the two species likely. Additionally, both types of paravertebral osteoderms differ strongly from the squarish and keeled paravertebral osteoderms of MB.R.3632. Therefore, even with the few preserved specimens of Alligatorium, assignment of MB.R.3632 to this genus can be excluded. Another species originally described as Alligatorium depereti Vidal, 1915 from Montsec in Spain, has been revised by Buscalioni \& Sanz (1988) and placed in the different genus Montsecosuchus instead. Montsecosuchus ("Alligatorium") depereti Vidal, 1915 differs from MB.R.3632 in its paravertebral osteoderms, which are like in Alligatorium meyeri, small, scute-like and unkeeled.

The genus Alligatorellus is known from three different individuals all assigned to one species, Alligatorellus beaumonti Gervais, 1871, from Cerin, Eichstätt and Wintershof. Due to the comparatively larger size and spatial difference of the Bavarian specimens to those of Cerin, Wellnhofer (1971) erected the two sub-species Alligatorellus beaumonti beaumonti (Cerin) and Alligatorellus beaumonti bavaricus (Bavaria), but there seem not to be any osteological differences between those sub-species. Alligatorellus beaumonti beaumonti is reconstructed to have a body length of $250 \mathrm{~mm}$, whereas Alligatorellus beaumonti bavaricus reaches a total body length of $300 \mathrm{~mm}$ (Wellnhofer 1971). All specimens of Alligatorellus are preserved with well developed osteodermal armour. The dorsal paravertebral osteoderms are squarish and imbricating, and possess a lateral keel. The caudal osteoderms are longitudinally oval with a median keel. Both the overlapping dorsal paravertebral osteoderms with lateral keel and the more oval caudal osteoderms with medial keel of Alligatorellus are strikingly similar to those osteoderms preserved in MB.R.3632. The only difference, a deeper sculpturing 
Table 2. Comparison of available limb ratios of all atoposaurid specimens with those of MB.R.3632, given collection numbers indicate that the specimens have been examined personally, whereas all other data are taken from Wellnhofer (1971). Closest matching ratios between MB.R.3632 and other atoposaurids are bold-face, indicating a mosaique-like pattern of similarities in limb proportions. Abbreviations: fe - femur; mc - metacarpale; mt - metatarsalia; NA - not available; ra radiale; ti - tibia.

\begin{tabular}{|c|c|c|c|c|c|c|c|}
\hline Specimens & fe : ti & fe $: m t ~ I I$ & $\mathrm{ti}: \mathrm{mt}$ II & $\mathrm{ra}: \mathrm{mc}$ I & ra: fe & ra : ti & ra : mtll \\
\hline MB.R.3632, Kelheim & 1.09 & 1.99 & 1.82 & 1.36 & 0.20 & 0.22 & 0.40 \\
\hline \multicolumn{8}{|l|}{ Atoposaurus } \\
\hline A. jourdani, Cerin & 1.06 & NA & NA & NA & 0.15 & 0.16 & NA \\
\hline A. jourdani, Cerin & 1.09 & NA & NA & NA & NA & NA & NA \\
\hline $\begin{array}{l}\text { A. oberndorferi, Kelheim } \\
\text { (PALMUC Nr. } 1964 \text { XXIV 44, cast) }\end{array}$ & 1.03 & 2.08 & 2.02 & 0.64 & 0.17 & 0.18 & 0.36 \\
\hline $\begin{array}{l}\text { A. oberndorferi, Schernfeld } \\
\text { (PALMUC 1901 I 12) }\end{array}$ & 1.04 & 2.04 & 1.97 & 1.36 & 0.21 & 0.21 & 0.42 \\
\hline \multicolumn{8}{|l|}{ Alligatorellus } \\
\hline A. beaumonti beaumonti, Cerin & 1.02 & 2.38 & 2.34 & & 0.18 & 0.18 & 0.43 \\
\hline A. beaumonti beaumonti, Cerin & 1.06 & 2.42 & 2.29 & NA & 0.19 & 0.20 & 0.46 \\
\hline $\begin{array}{l}\text { A. beaumonti bavaricus, Eichstätt } \\
\text { (PALMUC Nr. } 1937 \text { I 26) }\end{array}$ & 1.00 & 2.23 & 2.23 & NA & 0.19 & 0.19 & 0.42 \\
\hline $\begin{array}{l}\text { A. beaumonti bavaricus, Wintershof } \\
\text { (cast PALMUC) }\end{array}$ & 1.08 & 2.14 & 1.97 & 1.71 & 0.21 & 0.23 & 0.45 \\
\hline \multicolumn{8}{|l|}{ Alligatorium } \\
\hline A. meyeri, Cerin & ca. 1.08 & ca. 2.40 & 2.26 & 1.88 & ca. 0.21 & 0.23 & 0.51 \\
\hline A. franconicum, Painten & 1.09 & 2.03 & 1.86 & NA & NA & NA & NA \\
\hline $\begin{array}{l}\text { A. paintenense, Painten } \\
\text { (PALMUC Nr. } 1971 \text { I 104, cast) }\end{array}$ & 1.15 & ca. 1.96 & 1.70 & NA & NA & NA & NA \\
\hline \multicolumn{8}{|l|}{ Montsecosuchus } \\
\hline M. depereti, Montsec & 1.18 & 1.78 & 0.94 & NA & 0.15 & 0.18 & 0.30 \\
\hline
\end{tabular}

of the osteoderms in MB.R.3632, can be explained by ontogenetic variation, as MB.R.3632 is larger than all other specimens of Alligatorellus, and therefore represents an older ontogenetic age.

Although the taxon is not known from the SolnhofenEichstätt area, comparison between MB.R.3632 and the putative atoposaurid genus Theriosuchus should be mentioned for completeness. However, differences between Theriosuchus and specimen MB.R.3632 are clearly visible in the morphology of the tibia (Schwarz \& Salisbury 2005, fig. $7 \mathrm{j}$ ) and in the paravertebral osteoderms, which are angled and with peg-and-socket articulation in Theriosuchus (Owen 1879; Salisbury \& Frey 2001; Schwarz \& Salisbury 2005), so that a taxonomic assignment of MB.R.3632 to Theriosuchus is precluded. Additionally, MB.R.3632 differs from the putative atoposaurid Pachycheilosuchus from the Lower Cretaceous of Texas/USA (Rogers 2003) by its hatchet-shaped radiale, a tibia with a stronger cranially curved proximal head, and its keeled paravertebral osteoderms with a different outline.

The comparison of limb ratios preserved in MB.R.3632 and the different Solnhofen-Eichstätt atoposaurids (see Table 2) reveals a large variation in comparable limb proportions between the different taxa, different individuals of one species, and within the genus. Especially the interspecific variation in context with size differences indicates that limb ratios in atoposaurids are probably subject to ontogenetic changes. The strongest variation is found in the ratio of femur to Mt II lengths, and tibia to Mt II length. The similarities of limb ratios between MB.R.3632 and other atoposaurids seems to be distributed mosaic-like, and is even more difficult to assess, as some specimens have been lost or destroyed and therefore account for missing data. Generally, there seems to be no clear taxonomic signal from the limb proportions, which most plausibly can be explained by ontogenetic variation and the poor data available.

Comparable osteological features between these atoposaurids are therefore mainly restricted to the osteodermal armour, which differs between the different genera, in the case of Alligatorium even between different species, in the morphology of the paravertebral osteoderms. As mentioned above, paravertebral osteoderms are closely connected with the epaxial trunk musculature and in crocodylians play an important role in bracing of the trunk, and therefore in locomotion. Differences in their morphology, especially the presence and absence of special articulations and keels, can be taken 
as diagnostic at least on the generic level, at least within a given time frame and spatial restriction (Salisbury \& Frey 2001). The osteodermal armour of MB.R.3632 is strikingly similar to that of all individuals of Alligatorellus, and although there are some proportional differences between MB.R.3632 and Alligatorellus, an assignment to this taxon is made on the basis of the great similarities in osteoderm configuration.

\section{Taphonomy}

Although the described slab contains only an incomplete crocodyliform skeleton (with the rest having probably been destroyed by the quarry workers), the skeleton and its preservation indicate an "in situ" preservation of an atoposaurid crocodyliform, which has probably been washed as a carcass into the lagoon and was embedded there together with four marine echinoids. The echinoid remains are somewhat deeper sunken in the sediment bedding plane than the crocodyliform with its bones clearly overlaying the echinoid tests. Whereas the echinoids are entirely preserved (except for their spines), the crocodyliform is preserved in an intermediate stage of decomposition. The incompletely preserved right half of the specimen is disarticulated, although the bones are still partly associated. The paravertebral osteoderms are still arranged in a line with underlying vertebral fragments. The bones of the right hindlimb are still in association, although the single elements have been displaced already. The forelimb is incomplete and the right manus came to rest on top of one of the echinoids and disarticulated around it during decay (Fig. 1). The few preserved ribs and gastralia are scattered. A caudal vertebra, some osteoderms and two haemapophyses from the posterior region of the individual moved towards the trunk region. The position of all preserved skeletal elements in a context to each other makes it plausible that the carcass of the atoposaurid was not transported after it had sunk to the ground and disarticulation had started, implying that large scavengers were apparently absent. Only small scavengers, like crabs and small fishes as well as minor physical disturbance such as a weak current could have been responsible for the disarticulation of bones on the sediment surface.

The association of the skeleton with four specimens of the holectypoid echinoid Holectypus corallinus is coincidental. Both, the crocodyliform skeleton and the echinoids were embedded on the same bedding plane probably in a single event. The preservation of the echinoids is excellent and no signs of significant transport or reworking can be recognized. However, preservation of the echinoids suggests, that they died somewhat earlier than the crocodyliform and their empty and denuded tests were exposed on the sea floor for at least a short period. All four echinoids were embedded in their life position (i.e., with the oral surface facing downwards). However, we need to consider that the life position also represents the echinoid's most stable po-

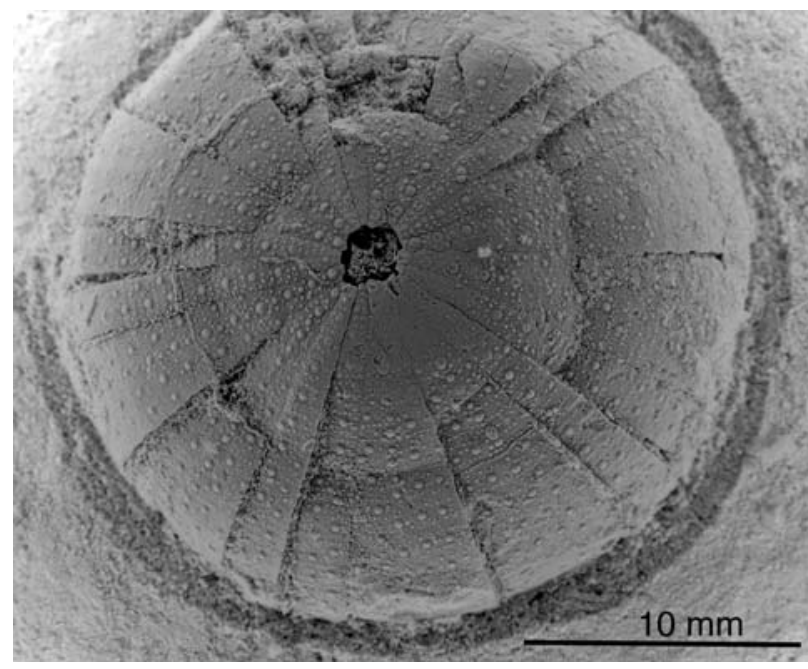

Figure 3. Detail of Holectypus corallinus D'Orbigny, 1850. Note the loss of the apical system. Digital imaging was carried out.

sition, due to the flat oral surface in contrast to the dome-shaped aboral part of the test. The tests of all four specimens are weakly compressed due to sediment compaction (Fig. 3). Although preservation of spines in their original position is a common phenomenon among echinoids found in the lithographic limestone (Bantz 1969; Grawe-Baumeister et al. 2000), attached spines were not observed in our material. All four specimens lack their spines, which have been fallen off after the echinoids died. Moreover, in one specimen the apical system has been lost (Fig. 3), indicating exposure on the sediment for a certain time, allowing an advanced state of decay. On the other hand, the fact that none of the specimens has been overgrown by biofouling organisms indicates that the exposure time on the seafloor was too short for epibiont colonization before final burial in the sediment. We suggest a within-habitat accumulation (i.e., the place of embedment is coincident with the place of life) of the sea urchins with very limited (if at all) transport and embedment of the echinoids in their most stable position (oral surface downwards). The delicate and lightweight spines, in contrast, have been washed away.

\section{Acknowledgements}

We are grateful to Günther Schweigert (Stuttgart) for providing information on the stratigraphy of the Kelheim locality. We thank Linda Tsuji (Berlin) and Dieter Korn (Berlin), as well as two anonymous reviewers for their substantial remarks that improved earlier versions of the manuscript. Tom Hübner (Hannover) is acknowledged for providing figures of atoposaurids from Munich, Oliver Rauhut (München) and Markus Moser (München) are thanked for given DSW access to the atoposaurid specimens in the Bavarian State Collection for Palaeontology and Geology in Munich. We thank the reviewers Angela Delgado Buscalioni, Attila Ösi and Chris Brochu for their helpful remarks and suggestions, as well as the editors Florian Witzmann and Dieter Korn for their efforts. 


\section{References}

Ammon, L. von 1905. Über jurassische Krokodile aus Bayern. Geognostische Jahreshefte 18 (4): 55-71.

Andrade, M. B. de, Young, M. T., Desojo, J. B. \& Brusatte, S. L. 2010. The evolution of extreme hypercarnivory in Metriorhynchidae (Mesoeucrocodylia: Thalattosuchia) based on evidence from microscopic denticle morphology. - Journal of Vertebrate Paleontology 30 (5): 1451-1465.

Bantz, H.-U. 1969. Echinoidea aus Plattenkalken der Altmühlalb und ihre Biostratinomie. - Erlanger geologische Abhandlungen 78: 1-35.

Brochu, C. A. 1996. Closure of neurocentral sutures during crocodilian ontogeny: Implications for maturity assessment in fossil archosaurs. - Journal of Vertebrate Paleontology 16 (1): 49-62.

Buscalioni, A. D. \& Sanz, J. L. 1988. Phylogenetic relationship of the Atoposauridae (Archosauria, Crocodylomorpha). - Historical Biology 1988 (1): 233-250.

Buscalioni, A. D. \& Sanz, J. L. 1990. Montsecosuchus depereti (Crocodylomorpha, Atoposauridae), new denomination for Alligatorium depereti Vidal, 1915 (Early Cretaceous, Spain): Redescription and phylogenetic relationships. - Journal of Vertebrate Paleontology 10 (2): 244-254.

D’Orbigny, A. 1850. Prodrome de Paléontologie Stratigraphique Universelle des Animaux Mollusques et Rayonnés faisant suite au Cours élémentaire de paléontologie et géologie stratigraphiques. Vol. II. Masson, Paris.

Farlow, J. O., Hurlburt, G. R., Elsey, R. M., Britton, A. R. C. \& Langston, W. J. 2005. Femoral dimensions and body size of Alligator mississippiensis: estimating the size of extinct mesoeucrocodylians. - Journal of Vertebrate Paleontology 25 (2): 354-369.

Frickinger, K. A. 1994. Die Fossilien von Solnhofen. Goldschneck Verlag, Weinstadt.

Frickinger, K. A. 1999. Die Fossilien von Solnhofen. Band 2: Neue Funde, neue Details, neue Erkenntnisse. Goldschneck Verlag, Weinstadt.

Gervais, P. 1871. Remarques au sujet des Reptiles provenant des calcaires lithographiques de Cirin, dans le Bugey, qui sont conservés au Musée de Lyon. - Comptes Rendus Sommaire des Seances de la Societe geologique de France 73: 603-607.

Grawe-Baumeister, J., Schweigert, G. \& Dietl, G. 2000. Echiniden aus dem Nusplinger Plattenkalk (Ober-Kimmeridgium, Südwestdeutschland). - Stuttgarter Beiträge zur Naturkunde B 286: 1-39.

Hay, O. P. 1930. Second Bibliography and Catalog of the Fossil Vertebrata of North America. Volume 2. Carnegie Institute, Washington.

Jourdan, C. 1862. Une communication de relative à deux noveaux fossiles trouvès dans le calcaire lithographique de Cirin. - Annales des Sciences Physiques et Naturelles de la Sociètè d'Agriculture et d' Industrie de Lyon 3rd series 6: 32-33.

Kuhn, O. 1961. Die Tier- und Pflanzenwelt des Solnhofer Schiefers. - Geologica Bavarica 48: 1-68.
Lauprasert, K., Laojumpon, C., Saenphala, W., Cuny, G., Thirakhupt, K. \& Suteethorn, V. 2010. Atoposaurid crocodyliforms from the Khorat Group of Thailand: first record of Theriosuchus from Southeast Asia. - Paläontologische Zeitschrift 85 (1): 37-47.

Martin, J., Rabi, M. \& Csiki, Z. 2010. Survival of Theriosuchus (Mesoeucrocodylia: Atoposauridae) in a Late Cretaceous archipelago: a new species from the Maastrichtian of Romania. - Naturwissenschaften 97 (9): 845-854.

Meyer, H. von 1850. Mitteilung, an Prof. Bronn gerichtet. - Neues Jahrbuch für Mineralogie 1850: 198.

Owen, R. 1879. Monograph on the fossil Reptilia of the Wealden and Purbeck Formations. Supplement IX, Crocodilia (Goniopholis, Brachydectes, Nannosuchus, Theriosuchus, and Nuthetes. - Palaeontographical Society, Monographs, Supplement IX 33: 1-19.

Rogers, J. V. I. 2003. Pachycheilosuchus trinquei, a new procoelous crocodyliform from the Lower Cretaceous (Albian) Glen Rose Formation of Texas. - Journal of Vertebrate Paleontology 23 (1): $128-145$.

Salisbury, S. W. \& Frey, E. 2001. A biomechanical transformation model for the evolution of semi-spheroidal articulations between adjoining vertebral bodies in crocodilians. In Grigg, G. C., Seebacher, F. \& Franklin, C. E. (eds). Crocodilian Biology and Evolution. Surry Beatty \& Sons, Chipping Norton: pp. 85-134.

Salisbury, S. W., Molnar, R. E., Frey, E. \& Willis, P. M. A. 2006. The origin of modern crocodyliforms: new evidence from the Cretaceous of Australia. - Proceedings of the Royal Society B 273: 2439-2448.

Schwarz, D. \& Salisbury, S. W. 2005. A new species of Theriosuchus (Atoposauridae, Crocodylomorpha) from the Late Jurassic (Kimmeridgian) of Guimarota, Portugal. - Geobios 38: 779-802.

Sereno, P. C., Larsson, H. C. E., Sidor, C. A. \& Gado, B. 2001. The giant crododyliform Sarcosuchus from the Cretaceous of Africa. - Science 294: 1516-1519.

Smith, A. B. 1985. Echinoid Palaeobiology. Allen \& Unwin, London.

Vidal, L. M. 1915. Nota geológica y paleontológica sobre el Jurásico de la provincia de Lérida. - Boletín del Instituto Geológico y Minero de España 26: 891-907.

Walker, A. D. 1970. A revision of the Jurassic reptile Hallopus victor (Marsh), with remarks on the classification of crocodiles. - Philosophical Transactions of the Royal Society of London B 257 (816): 323-372.

Wellnhofer, P. 1971. Die Atoposauridae (Crocodylia, Mesosuchia) der Oberjura-Plattenkalke Bayerns. - Palaeontographica A 138 (5-6): $133-165$.

Westphal, F. 1965. Ein neuer Krokodil-Fund aus dem Plattenkalk des Oberen Malms von Eichstätt (Bayern). - Neues Jahrbuch für Geologie und Mineralogie, Abhandlungen 123: 105-114.

Wu, X.-C., Sues, H.-D. \& Brinkman, D. B. 1996. An atoposaurid neosuchian (Archosauria: Crocodyliformes) from the Lower Cretaceous of Inner Mongolia (People's Republic of China). - Canadian Journal of Earth Sciences 33: 599-605. 